\title{
Coveiros e Saúde Laboral: pouco mais do que uma reflexão...
}

www.rpso.pt/coveiros-saude-laboral-pouco-do-reflexao/

April 26, 2017

\section{GRAVEDIGGERS AND OCUPATION HEALTH: LITTLE MORE THAN A REFLECTION...}

TIPO DE ARTIGO: Revisão Bibliográfica Integrativa

AUTORES: Santos M(1), Almeida A(2).

\section{RESUMO}

\section{Introdução/ enquadramento/ objetivos}

Os Coveiros estão sujeitos a diversos riscos/ fatores de risco; no entanto, a bibliografia associada é muito escassa.

\section{Metodologia}

Trata-se de uma Revisão Bibliográfica Integrativa, iniciada através de uma pesquisa realizada em abril de 2017, nas bases de dados "CINALH plus with full text, Medline with full text, Database of Abstracts of Reviews of Effects, Cochrane Central Register of Controlled Trials, Cochrane Database of Systematic Reviews, Cochrane Methodology Register, Nursing and Allied Health Collection: comprehensive, MedicLatina, Academic Search Complete e RCAAP".

\section{Conteúdo}

Coveiro é o indivíduo que abre as covas nos cemitérios e enterra os mortos. Nas funções atribuídas são ainda incluídas a retirada de corpos, inumações, transladações, exumações, serviços gerais de construção civil, limpeza, jardinagem, recolha e tratamento do lixo, prestação de informações/ portaria e manutenção geral. A irregularidade das tarefas associadas aos enterros permite intercalar com as restantes tarefas gerais. $O$ trabalho é pesado mas repartido, o que o torna menos árduo. Para além disso, na generalidade do tempo não há pressão, sendo frequentes as pausas durante o horário de trabalho.

\section{Conclusões}

Os principais fatores de risco nestes profissionais são manuseamento manual de cargas, posturas forçadas/ mantidas; queda de objetos; desconforto térmico; radiação ultravioleta; agentes biológicos; agentes químicos da limpeza; máquinas/instrumentos, ruido, vibrações e poeiras; turnos prolongados e/ou em horário pós-laboral; queda a níveis diferentes e soterramento. Quanto a medidas de proteção coletivas salientam-se o auxílio mecânico nas tarefas mais pesadas a nível de manuseamento de cargas e posturas forçadas/ mantidas, divisão da mesma carga por vários funcionários, rotatividade nas tarefas mais 
pesadas, intercalar tarefas com diferente patamar de dificuldade a nível de cargas; organização do serviço de forma a executar tarefas ao ar livre nas alturas do ano e do dia mais amenas, rotatividade nas tarefas e intercalar tarefas com diferentes desconfortos térmicos; organizar recursos que permitem uma correta higiene de mãos e corpo; usar agentes químicos e menos tóxicos possíveis, intercalar agentes com toxicidades diferentes, rotatividade de tarefas com agentes químicos mais prejudiciais e ter o menor número de funcionários expostos; usar máquinas modernas e em bom estado de conservação; diminuir a produção do ruido, potenciar o isolamento acústico, rotatividade para as tarefas mais ruidosas, intercalar tarefas com intensidade sonora diferente e ter o menor número de funcionários expostos; organizar os turnos de forma a evitar turnos prolongados e rotatividade das horas extra; formação para os riscos/ fatores de risco ocupacionais/ EPIs (equipamentos de proteção individual) e cumprimento rigoroso dos condicionamentos oficializados nas fichas de aptidão. A nível de EPIs poder-se-ão considerar luvas, calçado com biqueira de aço, farda, máscara, viseira e proteção auricular. Quanto a doenças profissionais fica subentendido a possibilidade de surgirem patologias herniárias, lesões músculo-esqueléticas, patologias oncológicas, eczemas alérgico ou de contato, asma e outras doenças respiratórias ou até mesmo hipoacusia/ surdez. Por fim, a nível de acidentes profissionais supõe-se que sejam mais prováveis as escoriações, contusões, fraturas e amputações.

Palavras/ expressões-chave: Coveiros; Saúde Ocupacional; Medicina do Trabalho.

\section{SUMMARY}

\section{Introduction / framework / objectives}

Gravediggers are subject to several risks / risk factors; however, the associated bibliography is very scarce.

\section{Methodology}

This is an Integrative Bibliographic Review, initiated through a survey conducted in April 2017, in the databases "CINALH plus with full text, Medline with full text, Database of Abstracts of Reviews of Effects, Cochrane Central Register of Controlled Trials, Cochrane Database of Systematic Reviews, Cochrane Methodology Register, Nursing and Allied Health Collection: comprehensive, MedicLatina, Academic Search Complete and RCAAP.

\section{Content}

Digger is the individual who opens the graves in the cemeteries and buries the dead. In the attributed functions are also included the removal of bodies, burials, transfers, exhumations, general civil construction services, cleaning, gardening, garbage collection and treatment, provision of information/ concierge and general maintenance. The irregularity of the tasks associated with funerals allows to interweave with the other general tasks. The work is heavy but divided, which makes it less arduous. In addition, in most of the time there is no pressure, with frequent breaks during working hours.

\section{Conclusions}

The main risk factors in these professionals are manual handling of loads, forced/ 
maintained postures; Falling objects; Thermal discomfort; Ultraviolet radiation; biological agents; chemical cleaning agents; machines/ instruments, noise, vibrations and dust; long shifts and/ or post-work hours; Falling to different levels and burial. Collective protection measures include mechanical assistance in the heaviest tasks in the handling of loads and forced/ maintained postures, division of the same load by several employees, rotation in the heavier tasks, intercalary tasks with different levels of difficulty level of loads; organization of the service in order to perform outdoor tasks at the heights of the year and day, churning tasks and intercalating tasks with different thermal discomforts; organize resources that allow correct hand and body hygiene; use the least toxic and chemical agents possible, intercalate agents with different toxicities, task turnover with more harmful chemical agents, and have the lowest number of employees exposed; Use modern machines in good condition; reduce the production of noise, promote acoustic insulation, rotate for the noisiest tasks, to intercalate tasks with different sound intensity and to have the fewest number of employees exposed; organize shifts to avoid prolonged shifts and overtime turnover; training for occupational hazards/ risk factors/ personal protective equipment (PPE) and strict compliance with the conditions officially established on the skill sheets. At the EPI level, gloves, footwear with a steel toe, a uniform, a mask, a visor and an ear protection can be considered. As for occupational diseases, the possibility of hernia pathologies, musculoskeletal injuries, oncological pathologies, allergic or contact eczema, asthma and other respiratory illnesses or even hearing loss/ deafness is implied. Finally, in the case of occupational accidents, it is assumed that bruises, fractures and amputations are more likely.

KEYWORDS: gravediggers, occupational health, occupational medicine.

\section{INTRODUÇÃO}

Os Coveiros estão sujeitos a diversos riscos/ fatores de risco; no entanto, a bibliografia associada é muito escassa, procurando quer em bases internacionais, quer nacionais.

\section{METODOLOGIA}

Pergunta protocolar: quais os principais riscos e fatores de risco existentes para os Coveiros, eventuais doenças profissionais associadas e medidas de proteção recomendadas?

Em função da metodologia PICo, foram considerados:

-P (population): coveiros

-I (interest): reunir conhecimentos relevantes sobre os principais riscos e fatores de risco existentes para os Coveiros, eventuais doenças profissionais associadas e medidas de proteção recomendadas, segundo os dados mais recentemente publicados

-C (context): saúde ocupacional nas empresas públicas (Câmaras) e privadas (que recrutam coveiros)

Foi realizada uma pesquisa em abril de 2017 nas bases de dados "CINALH plus with full text, Medline with full text, Database of Abstracts of Reviews of Effects, Cochrane Central Register of Controlled Trials, Cochrane Database of Systematic Reviews, Cochrane 
Methodology Register, Nursing and Allied Health Collection: comprehensive, MedicLatina e Academic Search Complete". Utilizando a palavra-chave "gravedigger" foram obtidos 5 artigos, com os critérios publicação igual ou superior a 2007 e acesso a texto completo; em função da língua original (portuguesa, inglesa ou espanhola) e da pertinência para o objetivo desta revisão, foram selecionados após a leitura do resumo e após a consulta do trabalho na íntegra, um artigo. Utilizando posteriormente as palavras-chave "burial, tomb e funerary", foram obtidos 476, 1 e 39 artigos; destes apenas se selecionou um artigo, o mesmo resultante da pesquisa anterior (artigo 2).

Contudo, como não se encontram estudos relativos à realidade portuguesa nestas bases de dados indexadas, os autores procuraram trabalhos inseridos no RCAAP (Repositório Científico de Acesso Aberto em Portugal). Aqui, utilizando a palavra-chave "coveiros", foram obtidos cinco documentos; após a leitura do resumo dos mesmos foram selecionadas três investigações; após a consulta na íntegra analisou-se apenas um documento (artigo 1). Foram procurados sinónimos, alguns até mais usados no Brasil (dado parte dos trabalhos nesta base de dados também se proveniente deste pais) e pesquisou-se também "enterrador, sepulteiro e sepultador"; contudo, não surgiram quaisquer artigos.

No quadro 1 pode ser consultada a caraterização dos artigos selecionados.

\section{CONTÉUDO}

A maioria dos dados inseridos neste artigo são provenientes de uma Tese de Mestrado de Gestão de Recursos Humanos. Neste trabalho foi analisada uma amostra de 31 coveiros inseridos em onze cemitérios da cidade do Porto.

A autora começa por definir que coveiro é o indivíduo que abre as covas nos cemitérios e enterra os mortos; também refere que considerou muito escassa a bibliografia encontrada. Nas funções atribuídas são ainda incluídas a retirada de corpos, as inumações (colocar o cadáver na sepultura), transladações (transportar os restos mortais da sepultura para outro local), exumações (abrir a sepultura para retirar os restos mortais), serviços gerais de construção civil, limpeza, jardinagem, recolha e tratamento do lixo, prestação de informações/ portaria e manutenção geral. A irregularidade das tarefas associadas aos enterros permite intercalar com as restantes tarefas gerais. O trabalho é pesado mas repartido, o que o torna menos árduo. Para além disso, na generalidade do tempo não há pressão, sendo frequentes as pausas para ir ao café conversar.

No contato inicial a autora considerou que esta amostra era muito reservada mas, após algum convívio, verificou que se tornaram até expansivos, na sua opinião.

A média de idade foi 50 anos (variando entre os 32 e os 67); na amostra todos os elementos, exceto um, pertenciam ao género masculino. Quanto a habilitações, quatro tinham o $12^{\circ}$ ano; sete o $9^{\circ}$, quatro o $6^{\circ}$ e 15 apenas a $3^{\circ}$ ou $4^{\text {a }}$ classes. Por sua vez, em relação ao estado civil, 24 eram casados, um estava viúvo, quatro eram solteiros e dois estavam divorciados. Quando analisada a antiguidade, três mantinham este trabalho desde a década de 70 , oito desde a de oitenta, três desde a década seguinte, nove desde 2000 e sete desde 2010. A média salarial mencionada foi de 600 euros (variando entre 485 e 800). O horário praticado na generalidade dos casos era de sete horas diárias, de segunda 
a sexta; as horas extras funcionavam à chamada/ por turnos. Entre os inquiridos, 19 afirmavam já ter progredido na carreira. Quando questionados perante a participação em ações de formação profissionais, apenas cinco já tinham tido essa oportunidade. Em relação à disponibilização de EPIs todos afirmaram ter luvas e máscara mas, também de forma unânime, estes últimos nunca eram utilizados.

Com o decorrer dos anos, surgiram máquinas que facilitam o serviço (comodumperescavadora/ transportadora de terra, ascensor e pulverizador) mas nem sempre os cemitérios as possuem ou têm espaço para a sua utilização.

Quanto a utensílios são realçados as pás, picaretas, enxadas, sacholas, alviões, vassouras, apanhadores, tesouras de poda e contentores de lixo. O incómodo que surge por utilizar estes objetos manuais é uma das queixas mais relevantes nestes profissionais.

Quando comparado o estado emocional no início da atividade, versus presente, verificouse que numa fase inicial dezoito referiram ansiedade, seis indiferença e quatro já gostavam das tarefas; presentemente apenas um referia ansiedade e seis gostavam do trabalho.

De forma unânime, os inquiridos demonstraram-se mais perturbados com enterros de crianças. Em relação aos familiares dos defuntos, referiram que sentiam mais dificuldades quando começavam a atirar a terra para cima do caixão. Afirmaram ainda que, neste contexto, tentavam demonstrar respeito/ compreensão/ pesar e profissionalismo, dignidade, prestar informações necessárias, ter boa apresentação, dar algum apoio moral, encorajamento ou simplesmente proporcionar algum silêncio.

Quanto ao preconceito relativo à profissão, a generalidade comenta que é um trabalho como outro qualquer e o que interessa é estar empregado: quinze afirmou não se importar, treze até tem orgulho e apenas um escondia a sua profissão.

Entre as atividades que consideram mais agradáveis referem as inumações e depois a manutenção; no inverso situam-se as exumações, enterros de crianças (como já se mencionou) e no inverno (devido ao desconforto térmico e às condições do solo).

Consideram que o serviço é complicado e que poucos estão interessados em nele exercer. Acham que deveriam ter acesso a um subsídio de risco, salário mais elevado, mais apoio de maquinaria, melhores condições de higiene, mais formação e isenção de trabalhar aos fins-de-semana e feriados.

Nesta tese de Mestrado tentou-se também inserir a perspetiva dos superiores hierárquicos. Neste sentido foi destacada a existência de um humor mórbido e pouco percetível para o exterior; também se salientou que os certificados de incapacidade temporário eram muito raros e que era muito frequente existirem problemas de alcoolismo, manifestado sobretudo pelas ausências em horário laboral para ir até o café ingerir tais bebidas, devido ao tempo livre e às gorjetas dos familiares dos defuntos (por serviços de informação, limpeza ou manutenção), agentes funerários, marmoristas e fábricas de velas (que utilizam o material de velas usadas para fazer novas).

Englobando a perspetiva dos familiares dos falecidos, estes destacaram a simpatia dos coveiros, a presença no local e o facto de fazerem favores sem pedir nada em troca. 
Desde a segunda metade do século passado que surgiram cursos de formação para este setor- os primeiros foram em Elvas, com sessões práticas e teóricas; depois foi criada a Escola de Operadores Cemiteriais, em alguns casos com a orientação da empresa Servilusa. Por exemplo, em relação aos cursos de cremação, por vezes têm de vir formadores estrangeiros. Outros temas formativos mencionados são a liderança, gestão de conflitos, gestão de stress, movimentação manual de cargas, noções básicas de primeiros socorros, como lidar com o luto e técnicas de comunicação verbal e não verbal.

A aceitação da cremação pela igreja católica fez com que esta aumentasse; em 2007 existiam quatro fornos crematórios em território nacional e agora são dezassete. 0 processo é mais ecológico e mais barato: varia de 178 euros em horário laboral até 500 a 720 se extralaboral; pela Servilusa o custo é sempre de 195 euros, independentemente do horário e em todos os casos já incluindo o pote para as cinzas... face uma média de 1500 euros para um enterro clássico, sem considerar as despesas associadas à compra do terreno no cemitério e montagem da campa. Contudo, ainda assim, a taxa de cremação é de apenas $6 \%$, ainda que esteja a aumentar. A menor disponibilidade para colocar flores na campa e limpezas associadas, também pode contribuir para o aumento da cremação.

Para uniformizar as normas de conduta foi criado um código de ética. Este incide sobretudo na necessidade de cumprir as tarefas necessárias, proteger o património, usar ferramentas adequadas e em bom estado, usar EPIs e cumprir as normas de Higiene e Segurança, encaminhar corretamente os resíduos, atualizar o conhecimento, ter bom trato (com os familiares dos defuntos, colegas e chefias), ser discreto e reservado, não beber álcool durante o horário de trabalho nem chegar alcoolizado no início do turno, não fumar nas áreas de acesso público, silenciar telemóveis durante os enterros, pedir a um colega que o substitua se necessitar de se ausentar e não aceitar ofertas de clientes ou fornecedores, exceto se estas não exigirem contrapartidas profissionais e se forem comunicadas ao superior hierárquico.

Este avalia o desempenho através dos conhecimentos demonstrados e capacidade de aprendizagem, atitude, rigor (na organização, cumprimento de prazos, priorização e eficácia na gestão do tempo), iniciativa (tomar decisões, assumir riscos) e capacidade para trabalho em equipa. A classificação final assumirá um dos seguintes patamares: não satisfaz, satisfaz pouco, satisfaz, satisfaz bastante e excelente. O alcoolismo é neste setor uma importante causa de indisciplina e absentismo.

O outro artigo selecionado acrescenta pouca informação ao já exposto... ainda assim poder-se-á realçar que estes autores enfatizaram que se trata de um trabalho com exigências físicas e emocionais, com pouca visibilidade para a sociedade em geral e geralmente considerado como pouco saudável e até repulsivo (às vezes, até mesmo na sua própria casa, pelos familiares). Este trabalho menciona de forma muito sucinta a possibilidade surgirem lesões músculo-esqueléticas e doenças infeciosas.

Principais riscos/ fatores de risco

Ainda que quase não mencionados nos artigos selecionados, os autores destacam neste contexto:

-manuseamento manual de cargas, posturas forçadas/ mantidas; queda de objetos 
-desconforto térmico (muito frio, muito calor, humidade) com a eventual alteração na coordenação motora e acidentes associados; bem como a radiação ultravioleta

-agentes biológicos

-agentes químicos da limpeza e a nível dos serviços de manutenção

-manuseamento de máquinas/instrumentos, ruido, vibrações e poeiras

-turnos prolongados e/ou em horário pós-laboral

-queda a níveis diferentes e soterramento

Medidas de proteção coletiva

Neste sentido poderão ser considerados:

-auxílio mecânico nas tarefas mais pesadas a nível de manuseamento de cargas e posturas forçadas/ mantidas, divisão da carga por vários funcionários, rotatividade nas tarefas mais pesadas, intercalar tarefas com diferente patamar de dificuldade a nível de cargas

-organização do serviço de forma a executar tarefas ao ar livre nas alturas do ano e do dia mais amenas; rotatividade nas tarefas e intercalar tarefas com diferentes desconfortos térmicos

-organizar recursos que permitem uma correta higiene de mãos e corpo

-usar agentes químicos o menos tóxicos possíveis, intercalar agentes com toxicidades diferentes, rotatividade de tarefas com agentes químicos mais prejudiciais

-usar máquinas modernas e em bom estado de conservação

-diminuir a produção do ruido, potenciar o isolamento acústico, rotatividade para as tarefas mais ruidosas e intercalar tarefas com intensidade sonora diferente

-organizar os turnos de forma a evitar turnos prolongados; rotatividade das horas extra -formação para os riscos/ fatores de risco ocupacionais/ EPIs

-cumprimento dos condicionamentos oficializados nas fichas de aptidão

Equipamentos de proteção individual

-luvas, calçado com biqueira de aço

-farda adequada à temperatura ambiente e nível de humidade, preferencialmente constituída por várias camadas sobreponíveis

-máscara, viseira

-proteção auricular

Eventuais doenças profissionais 
Aqui poder-se-ão considerar situações tão diversas quanto patologia herniária (discal, inguinal, umbilical), lesões músculo-esqueléticas (tendinites, tenossinovites), patologias oncológicas (pele, pulmão...), eczemas alérgico ou de contato, asma e outras doenças respiratórias ou até mesmo hipoacusia/ surdez.

Eventuais acidentes laborais

A este nível os autores realçam sobretudo as escoriações, contusões, fraturas e amputações.

\section{CONCLUSÕES}

Os principais fatores de risco nestes profissionais são manuseamento manual de cargas, posturas forçadas/ mantidas; queda de objetos; desconforto térmico; radiação ultravioleta; agentes biológicos; agentes químicos; máquinas/instrumentos, ruido, vibrações e poeiras; turnos prolongados e/ou em horário pós-laboral; queda a níveis diferentes e soterramento. A nível de medidas de proteção coletivas salientam-se o auxílio mecânico nas tarefas mais pesadas a nível de manuseamento de cargas e posturas forçadas/ mantidas, divisão da carga por vários funcionários, rotatividade nas tarefas mais pesadas, intercalar tarefas com diferente patamar de dificuldade a nível de cargas; organização do serviço de forma a executar tarefas ao ar livre nas alturas do ano e do dia mais amenas, rotatividade nas tarefas e intercalar tarefas com diferentes desconfortos térmicos; organizar recursos que permitem uma correta higiene de mãos e corpo; usar agentes químicos o menos tóxicos possíveis, intercalar agentes com toxicidades diferentes, rotatividade de tarefas com agentes químicos mais prejudiciais; usar máquinas modernas e em bom estado de conservação; diminuir a produção do ruido, potenciar o isolamento acústico, rotatividade para as tarefas mais ruidosas e intercalar tarefas com intensidade sonora diferente; organizar os turnos de forma a evitar turnos prolongados e rotatividade das horas extra; formação para os riscos/ fatores de risco ocupacionais/ EPIs e cumprimento rigoroso dos condicionamentos oficializados nas fichas de aptidão. A nível de EPIs poder-se-ão considerar luvas, calçado com biqueira de aço, farda adequada, máscara, viseira e proteção auricular. Quanto a doenças profissionais fica subentendido a possibilidade de surgirem patologias herniárias, lesões músculo-esqueléticas, patologias oncológicas, eczemas alérgico ou de contato, asma e outras doenças respiratórias ou até mesmo hipoacusia/ surdez. Por fim, a nível de acidentes profissionais são mais prováveis as escoriações, contusões, fraturas e amputações.

Este setor profissional envolve um pequeno número de trabalhadores (a nível nacional) mas trata-se de uma área pouco estudada e com muito poucos trabalhos publicados. Seria muito pertinente que os profissionais das Equipas de Saúde Ocupacional a trabalhar nesta área investigassem o tema e divulgassem/ publicassem as suas conclusões.

\section{CONFLITOS DE INTERESSE, QUESTÕES ÉTICAS E/OU LEGAIS}

Nada a declarar.

\section{AGRADECIMENTOS}

Nada a declarar. 


\section{BIBLIOGRAFIA}

1)Jacques M. Os Coveiros enquanto Recursos Humanos. Tese de Mestrado em Gestão de Recursos Humanos. ISLA. 2012, 1-119.

2)Pinheiro F, Ficher F, Cobianchi C. Work of gravediggers and health. Work 41. 2012, 5819-5822.

Fluxograma de $1^{\mathrm{a}}$ fase

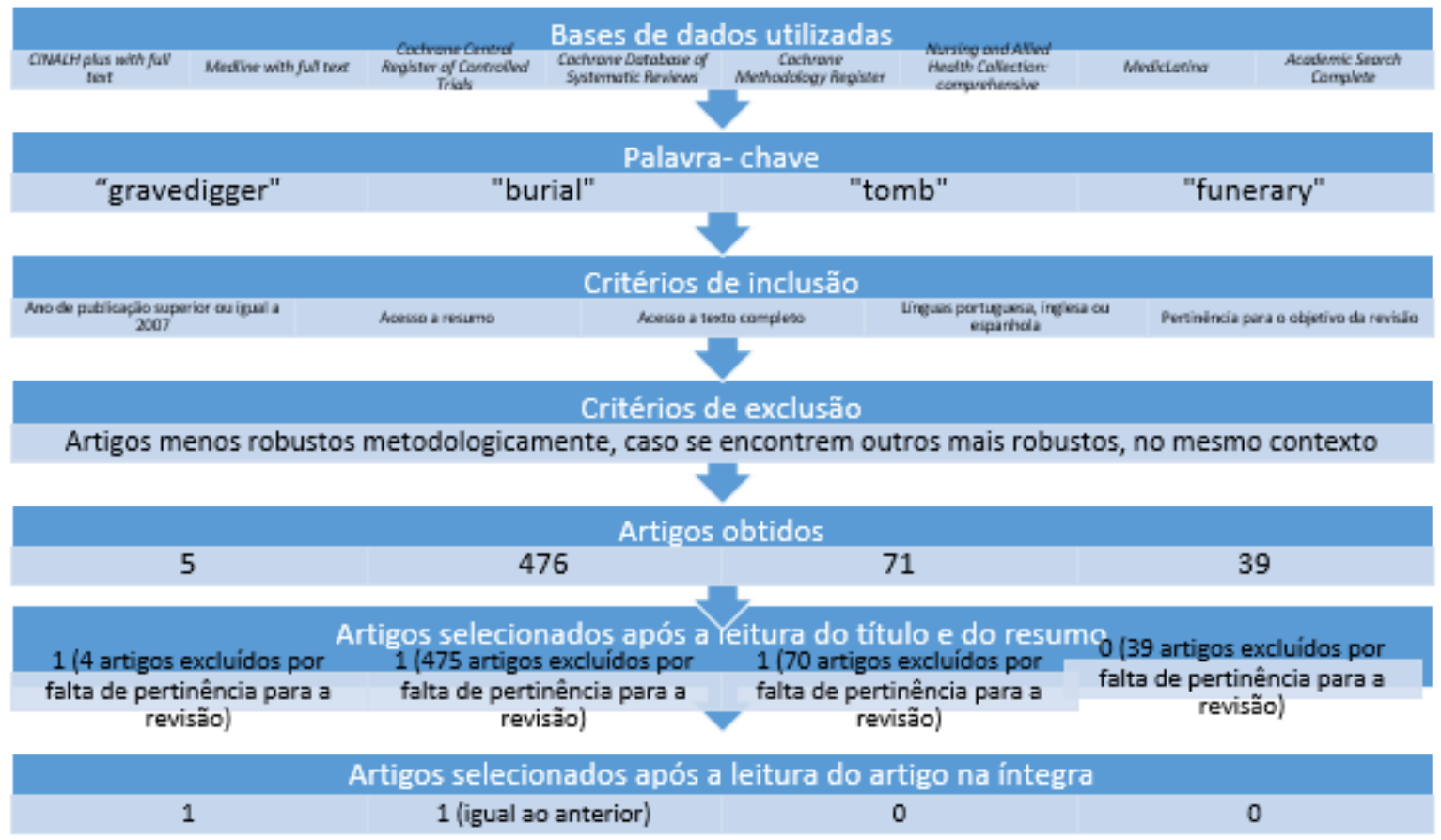

Fluxograma de $2^{\mathrm{a}}$ fase

\begin{tabular}{|c|c|c|}
\hline \multicolumn{3}{|c|}{ RCAAP } \\
\hline \multicolumn{3}{|c|}{ Palavra- chave } \\
\hline coveiros & enterrador sepulteiro & sepultador \\
\hline \multicolumn{3}{|c|}{ Critérios de inclusão } \\
\hline 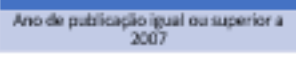 & 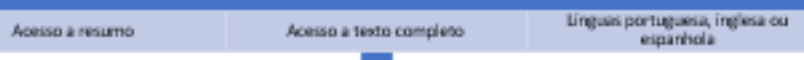 & Pertinincie para a etiptivo de revidio \\
\hline \multicolumn{3}{|c|}{ Critérios de exclusão } \\
\hline \multirow{2}{*}{\multicolumn{3}{|c|}{ Artigos menos robustos metodologicamente, caso se encontrem outros mais robustos, no mesmo contexto }} \\
\hline & & \\
\hline 5 & 0 & 0 \\
\hline \multicolumn{3}{|c|}{ Artigos selecionados após a leitura do título e do resumo } \\
\hline 3 & $\begin{array}{ll}0 & 0\end{array}$ & 0 \\
\hline
\end{tabular}

Quadro 1- Classificação Metodológica e Caraterização do artigos consultados 
1 Observacional

Analítico

Transversal
Nesta tese de mestrado a autora avaliou uma amostra de 31 coveiros a trabalhar no Porto. Após a caraterização de funções, é descrita a idade dos elementos da amostra, habilitações e estado civil. São proporcionadas informações relativas à antiguidade, salário, horário, progressão na carreira, existência e uso de EPIs, máquinas e instrumentos disponíveis, estado emocional, preconceito sentido, atividades mais agradáveis e desagradáveis, opinião dos superiores hierárquicos e dos familiares dos falecidos, bem como formação, noções sobre cremação, código de ética e avaliação de desempenho. abordando de forma superficial as tarefas/ exigências, visão da sociedade sobre este setor profissional e algumas doenças associadas.

(1) Licenciada em Medicina; Especialista em Medicina Geral e Familiar; Mestre em Ciências do Desporto; Especialista em Medicina do Trabalho; Presentemente a exercer nas empresas Medicisforma, Clinae, Servinecra e Serviço Intermédico; Diretora Clínica da empresa Quercia; Diretora da Revista Portuguesa de Saúde Ocupacional on line; Endereços para correspondência: Rua Agostinho Fernando Oliveira Guedes, 42 4420-009 Gondomar; s_monica_santos@hotmail.com.

(2) Mestre em Enfermagem Avançada; Especialista em Enfermagem Comunitária; Pós-graduado em Supervisão Clínica e em Sistemas de Informação em Enfermagem; Docente na Escola de Enfermagem (Porto), Instituto da Ciências da Saúde da Universidade Católica Portuguesa; Diretor Adjunto da Revista Portuguesa de Saúde Ocupacional on line; aalmeida@porto.ucp.pt.

Santos M, Almeida A. Coveiros e Saúde Laboral: pouco mais do que uma reflexão... Revista Portuguesa de Saúde Ocupacional. 2017, volume 3, 1-7. 